\title{
In situ growth of blue-emitting thin films of cerium-doped barium chloride hydrate at low temperatures
}

\author{
Jianhua $\mathrm{Hao}^{\mathrm{a})}$ \\ Department of Physics, The University of Hong Kong, Pokfulam Road, Hong Kong and Thin-Film \\ Semiconductor Laboratory, Department of Chemistry, University of Guelph, Guelph, \\ Ontario N1G 2W1 Canada \\ Zhidong Lou and Michael Cocivera \\ Thin-Film Semiconductor Laboratory, Department of Chemistry University of Guelph, Guelph, \\ Ontario N1G 2W1, Canada
}

(Received 11 October 2002; accepted 15 January 2003)

\begin{abstract}
Blue emission was observed from thin films of barium chloride hydrate doped with cerium. The films were deposited by spray pyrolysis of aqueous solutions with substrate temperatures between 250 and $450{ }^{\circ} \mathrm{C}$. The cathodoluminescence (CL) spectrum consists of two peaks at 443 and $485 \mathrm{~nm}$ due to $4 f-5 d$ transitions of cerium ion. The dependence of the emission band on deposition temperature and $\mathrm{Ce} / \mathrm{Ba}$ ratio is discussed. The CL luminance and luminous efficiency at $5 \mathrm{kV}$ were $120 \mathrm{~cd} / \mathrm{m}^{2}$ and $0.48 \mathrm{~lm} / \mathrm{W}$, respectively, for the films deposited at temperatures as low as $250{ }^{\circ} \mathrm{C}$. The results indicate barium chloride hydrate doped with cerium is a blue phosphor that exhibits relatively efficient luminescence after processing at low temperatures. (C) 2003 American Institute of Physics. [DOI: 10.1063/1.1558891]
\end{abstract}

Cerium-activated materials have been studied extensively in the last several decades. These studies were directed to a variety of applications, such as optoelectronics, flatpanel displays, and $\mathrm{x}$-ray imaging systems. Recently, Cedoped thin films, such as $\mathrm{Y}_{2} \mathrm{SiO}_{5}$ and $\mathrm{SrGa}_{2} \mathrm{~S}_{4}$, have been shown to produce blue emission. ${ }^{1-3}$ However, because asgrown films are usually amorphous or have poor crystallinity, annealing them at relatively high temperatures was required for both crystallization of compounds and diffusion of $\mathrm{Ce}$ ions before sufficient brightness was obtained. Unfortunately, high temperature processes are not suitable for some applications involving displays that require glass substrates. Considerable research is being focused on in situ growth of Ce-doped thin films. Recently, Tanaka et al. ${ }^{4}$ observed cathodoluminescence (CL) from thin films of $\mathrm{SrGa}_{2} \mathrm{~S}_{4}$ :Ce deposited in situ using a molecular beam epitaxy. They considered the growth temperature of the films $\left(472.5^{\circ} \mathrm{C}\right)$ to be the lowest value ever achieved. While improving the deposition process for the thin films of existing Ce-activated hosts is important, it is known that quantum efficiencies of variety of cerium-doped hosts can differ substantially. ${ }^{5}$ Thus, it is desirable to investigate other host materials for $\mathrm{Ce}$ ion.

For alkaline earth halide lattices, $\mathrm{BaF}_{2}$ : $\mathrm{Ce}$ has attracted much attention as a scintillator material. ${ }^{6}$ Besides that, only photoluminescence in bulk of Ce-doped alkaline earth $(\mathrm{Ca}$, $\mathrm{Sr}, \mathrm{Ba})$ chlorides had been observed in the UV region (330$400 \mathrm{~nm}){ }^{7}$ There is little work on the CL study of alkaline earth chlorides. In this letter, the blue CL characteristics at room temperature are reported for thin films of barium chloride hydrate doped with cerium. Spray pyrolysis was used to deposit the films. The films were grown in situ from 250 to $450^{\circ} \mathrm{C}$, and no postannealing was employed.

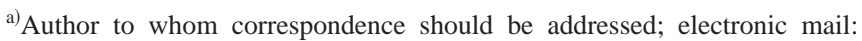
jhhao@khu.hk
}

Thin films of $\mathrm{BaCl}_{2} \cdot 2 \mathrm{H}_{2} \mathrm{O}$ :Ce were deposited on Corning 7059 glass substrates by a spray pyrolysis technique. The starting materials were $0.1 \mathrm{M} \mathrm{BaCl} 2$ (anhydrous and 99.998\% from Alfa) and $\mathrm{CeCl}_{3}$ (anhydrous and $99.5 \%$ from Alfa). The stock precursor solutions were mixed in an appropriate ratio to provide solutions in the range of 5-15 at. \% Ce dopant relative to $\mathrm{Ba}$. The spray system was described in detail elsewhere. ${ }^{8}$ Briefly, the spray, which was developed by an ultrasonic nebulizer, was directed towards the substrate. The spray chamber was mounted on an $x-y$ translation table to raster the aerosol to cover an area of $25 \times 50 \mathrm{~mm}^{2}$. Humid air was used as a carrier gas at a flow of $1.2 \mathrm{~L} / \mathrm{min}$ rate.

The crystal structure determination and phase identification of the films were carried out using a Rigaku Geigerflex II x-ray diffractometer (XRD) with $\mathrm{Co} K \alpha$ radiation. The chemical composition of thin films was analyzed by using induced coupled plasma (ICP) atomic absorption spectroscopy and energy dispersive x-ray spectroscopy (EDS). The morphology of the films was observed by a field emission scanning electron microscopy (FE-SEM) (Hitachi S-4500). The CL spectra were obtained using a CL luminoscope (Relion Industries ELM-2B). Luminescence spectra were measured using an Ocean Optics S2000 charge coupled device spectrometer $(350-900 \mathrm{~nm})$. The spectrometer provides a resolution of $1.5 \mathrm{~nm}$ of the full width at half maximum. A Minolta T-1M illuminance meter was used to determine the luminance of the films.

Figure 1(a) shows the XRD spectrum of an as-grown thin film deposited at $250{ }^{\circ} \mathrm{C}$. For comparison, a standard $\mathrm{BaCl}_{2} \cdot 2 \mathrm{H}_{2} \mathrm{O}$ powder pattern from the JADE-PDF card No. 25-1135 is presented in Fig. 1(b). Figure 1(a) illustrates that the as-grown film deposited at $250^{\circ} \mathrm{C}$ formed a polycrystalline structure. All diffraction peaks of XRD agreed well with $\mathrm{BaCl}_{2} \cdot 2 \mathrm{H}_{2} \mathrm{O}$ having monoclinic structure $(a=6.72$, $b=10.91, c=7.14)$. We excluded some possible compounds, 


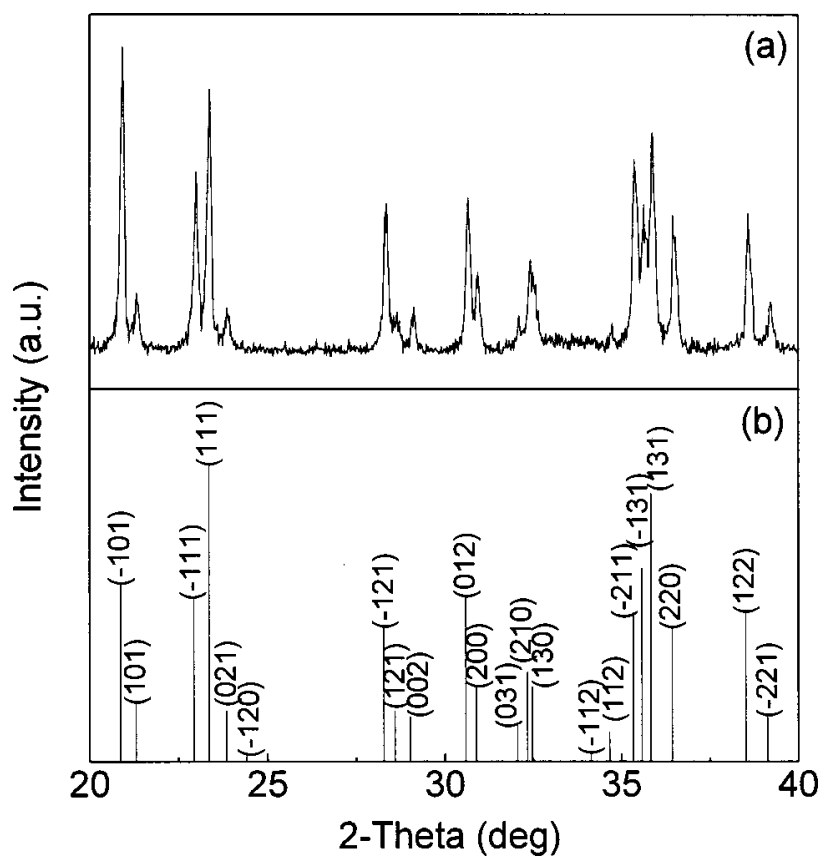

FIG. 1. XRD patterns for $\mathrm{BaCl}_{2} \cdot 2 \mathrm{H}_{2} \mathrm{O}$ :Ce thin films grown on glass substrates: (a) as-grown at $250^{\circ} \mathrm{C}$, (b) standard $\mathrm{BaCl}_{2} \cdot 2 \mathrm{H}_{2} \mathrm{O}$ powder pattern from the JADE-PDF card No. 25-1135.

such as $\mathrm{BaCl}_{2}, \mathrm{BaO}$, and $\mathrm{Ba}_{4} \mathrm{Cl}_{6} \mathrm{O}$ by comparing their standard power patterns with Fig. 1(a). These results indicate that sprayed thin films of $\mathrm{BaCl}_{2} \cdot 2 \mathrm{H}_{2} \mathrm{O}$ crystallized at an exceptionally low temperature in comparison with other thin film materials grown by this technique. ${ }^{9-11}$ In those cases the asgrown thin films showed no or broad peaks of x-ray pattern, indicating poor crystallization.

Figure 2 shows the FE-SEM image of thin films deposited at $250{ }^{\circ} \mathrm{C}$. The films exhibited much less dense morphology. The highly porous structure was formed over the whole film.

Figure 3 shows the CL spectra of the as-grown films for different $\mathrm{Ce}$ concentration relative to $\mathrm{Ba}$ in the spray solutions. All films deposited at $250^{\circ} \mathrm{C}$ were about $1.5 \mu \mathrm{m}$ thick. ICP analysis revealed that the ratio of $\mathrm{Ce}$ and $\mathrm{Ba}$ measured in the films was about one-third of that in the spray solution, due to different sticking probability for each element. A $5 \mathrm{kV}$ excitation voltage was used for CL measurement at room temperature. The current density on the sample surface was

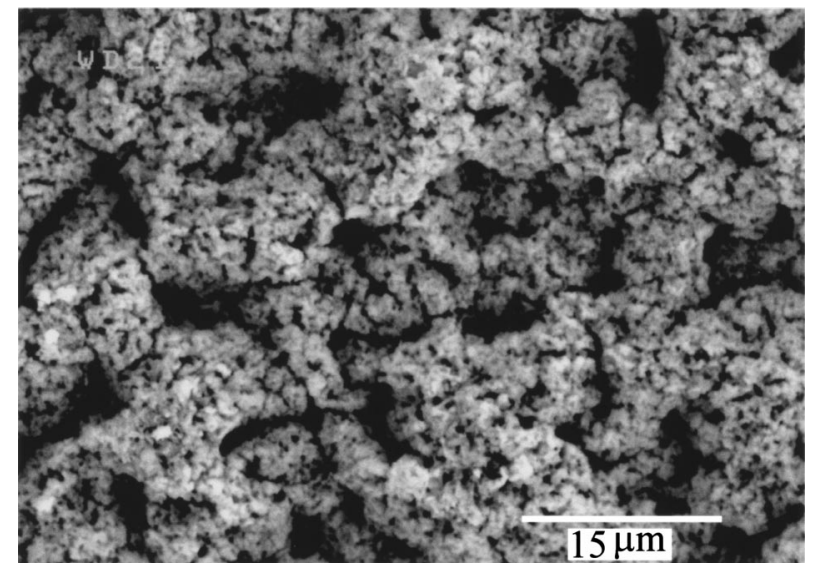

FIG. 2. FE-SEM image of $\mathrm{BaCl}_{2} \cdot 2 \mathrm{H}_{2} \mathrm{O}$ :Ce thin films deposited at $250{ }^{\circ} \mathrm{C}$.

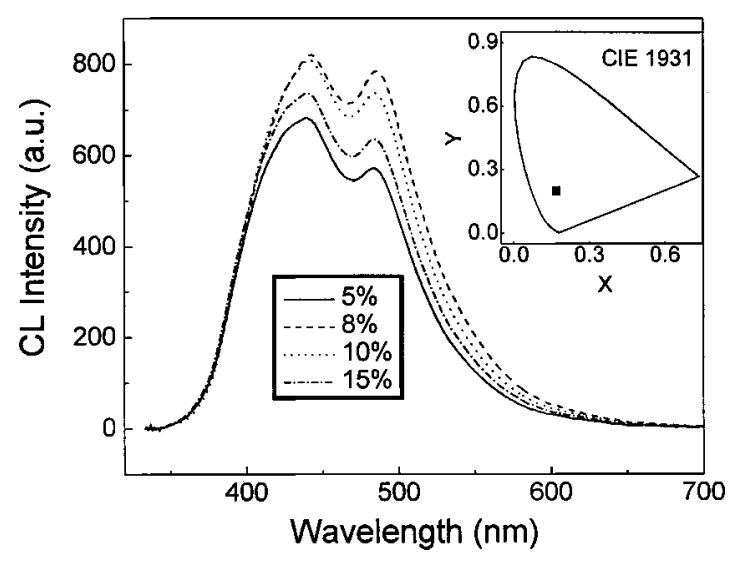

FIG. 3. CL for $\mathrm{BaCl}_{2} \cdot 2 \mathrm{H}_{2} \mathrm{O}$ :Ce thin films doped with different Ce concentration relative to $\mathrm{Ba}$ in the spray solutions. A CIE chromaticity diagram showing the chromaticity point is presented in inset.

estimated to be $62 \mu \mathrm{A} / \mathrm{cm}^{2}$ for a beam current of $0.5 \mathrm{~mA}$. The CL spectra of the as-grown films deposited at $250{ }^{\circ} \mathrm{C}$ exhibited broad multibands covering the blue region, which consisted of two peaks at 443 and $485 \mathrm{~nm}$. For comparison, the emission spectrum of cerium-doped anhydrous barium chloride had a maximum at $352 \mathrm{~nm}$ and a shoulder at 380 $\mathrm{nm}^{7}$ The emission maximum shifted from 352 to $360 \mathrm{~nm}$ with increasing activator concentration from $0.05 \%$ to $5 \%$. Our characteristic emission bands are similar to those exhibited in other Ce-activated hosts, like $\mathrm{Y}_{2} \mathrm{SiO}_{4}$ and $\mathrm{SrGa}_{2} \mathrm{~S}_{4} \cdot{ }^{1-4}$ The overlapping bands in Fig. 3 correspond to two allowed $4 f-5 d$ transitions of $\mathrm{Ce}^{3+} \cdot{ }^{12}$ Furthermore, the line position did not change as the Ce concentration changed, showing that the nature of the cerium activation did not change with concentration. However, the CL intensities changed with Ce concentration. Consequently, the film from $8 \%$ Ce-dopant solution had the maximum intensity, indicating self-quenching at the higher concentrations. The location of the color coordinates of $\mathrm{BaCl}_{2} \cdot 2 \mathrm{H}_{2} \mathrm{O}$ :Ce thin films on the CIE chromaticity diagram is presented in the inset of Fig. 3. The chromaticity coordinates were $x=0.169$ and $y=0.199$ with a dominant wavelength of $480 \mathrm{~nm}$ and $68 \%$ color purity.

For films grown at various substrate temperatures, Fig. 4

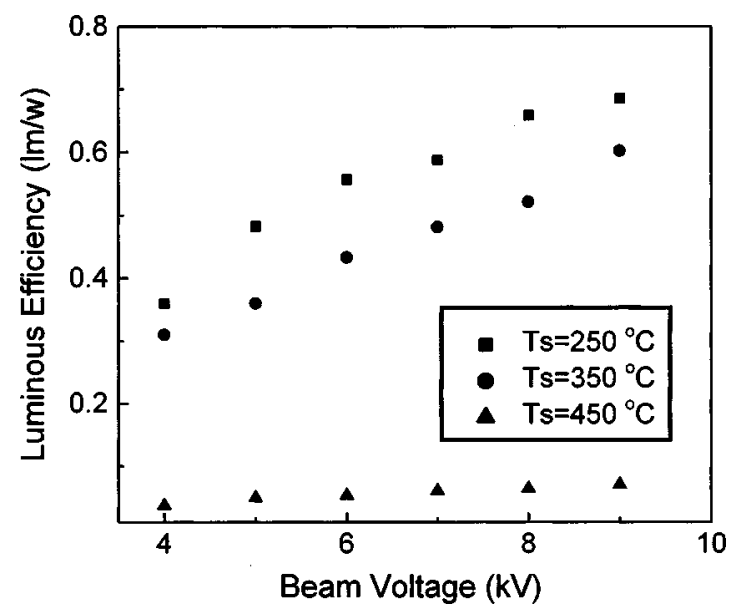

FIG. 4. Variation of CL luminous efficiency of $\mathrm{BaCl}_{2} \cdot 2 \mathrm{H}_{2} \mathrm{O}$ :Ce thin films deposited at various substrate temperatures as a function of electron beam voltage. The current density on the films was $62 \mu \mathrm{A} / \mathrm{cm}^{2}$. 
shows the dependence of the CL efficiency as a function of electron beam voltage. The CL efficiency increased continually as the acceleration voltage increased from 4 to $9 \mathrm{kV}$ at a constant current density of $62 \mu \mathrm{A} / \mathrm{cm}^{2}$, and saturation was not evident. In our measurements, the luminescence was measured on the side irradiated by the electron beam, and the lower efficiency at low voltage indicates that the transfer of the recombination energy of the electron-hole pair to a luminescent ion occurred with lower probability near the surface than deeper in the film. In addition, the CL increase could be attributed to an increase in electron penetration depth as applied voltage is increased, resulting in an increase in the number of $\mathrm{Ce}^{3+}$ ions that can luminescence. In general, the dependence of CL brightness $L_{\mathrm{CL}}$ on the electron beam current and voltage for many phosphors is governed by $L_{\mathrm{CL}}$ $=f\left(I_{b}\right)\left(V-V_{0}\right)^{m}$, where $V_{0}$ is a "dead voltage" and 1 $\leqslant m \leqslant 2$ for most phosphors. ${ }^{13}$ Typically, the CL luminance and luminous efficiency at $5 \mathrm{kV}$ were $120 \mathrm{~cd} / \mathrm{m}^{2}$ and 0.48 $\mathrm{lm} / \mathrm{W}$, respectively, for the film deposited at $250^{\circ} \mathrm{C}$.

On the other hand, the luminous efficiency decreased significantly for all excitation voltages when the growth temperature increased. This observation could be due to a decrease of amount of $\mathrm{Cl}$ remaining in thin films with increasing growth temperature. This was in evidence from the EDS analysis of thin films. As the growth temperature was increased, most $\mathrm{Cl}$ was replaced by the oxygen element. This result is consistent with the observation of other films prepared from chloride solutions. ${ }^{14}$ Furthermore, the XRD of the films grown at $450{ }^{\circ} \mathrm{C}$ exhibited very weak peaks, perhaps associated with $\mathrm{BaO}$, indicating that the films had poor crystallinity.

From a practical point of view, the stability and morphology play important roles in the performance of the final phosphor. ${ }^{15}$ Preliminary studies showed that there is no obvious change for the CL of the films in ambient atmosphere for two months, showing that is relatively stable material. However, about $20 \%$ of the decrease from initial values of CL was observed during the first 1 min of electron beam operation for all samples measured both before and after two months. This phenomenon could be related to either halide instability or the relaxation behavior of CL observed in other phosphors. ${ }^{16}$ The porosity of the films shown in Fig. 2 could cause the reduction of resolution and efficiency in some phosphor screen applications. If the precursor solutions with lower concentration are used to deposit the films, the films would become denser and it will result in the improvement of the performance.

In summary, as-grown thin films of cerium-doped barium chloride hydrate exhibit blue CL emission, and CL intensity decreased significantly with increasing the growth temperature between 250 and $450^{\circ} \mathrm{C}$. Our results indicate that the material studied as thin film phosphor is rather unique since it contains water. It seems that the $4 f-5 d$ transition in $\mathrm{Ce}$ is so energetic that the $\mathrm{O}-\mathrm{H}$ phonons cannot disturb it.

The authors would like to thank Dr. Julie De Merchant for help in ICP measurement and Andrew Moore for help in FE-SEM/EDS measurements.

${ }^{1}$ X. Ouyang, A. H. Kitai, and T. Xiao, J. Appl. Phys. 79, 3229 (1996).

${ }^{2}$ H. Nakajima, H. Kominami, T. Aoki, Y. Nakanishi, and Y. Hatanaka, J. Lumin. 87-89, 1146 (2000).

${ }^{3}$ Y. Nakanishi, H. Nakajima, N. Uekura, H. Kominami, M. Kottaisamy, and Y. Hatanaka, J. Electrochem. Soc. 149, H165 (2002).

${ }^{4}$ K. Tanaka, S. Okamoto, H. Kominami, Y. Nakanishi, X. Du, and A. Yoshikawa, J. Appl. Phys. 92, 834 (2002); S. Okamoto, K. Tanaka, and Y. Inoue, Appl. Phys. Lett. 76, 946 (2000).

${ }^{5}$ M. Raukas, S. A. Basun, W. van Schaik, W. M. Yen, and U. Happek, Appl. Phys. Lett. 69, 3300 (1996).

${ }^{6}$ A. J. Wojtowicz, P. Szupryczynski, J. Glodo, W. Drozdowski, and D. Wisniewski, J. Phys.: Condens. Matter 12, 4097 (2000).

${ }^{7}$ W. Li and M. Leskela, Mater. Lett. 28, 491 (1996).

${ }^{8}$ N. Golego and M. Cocivera, Thin Solid Films 322, 14 (1998)

${ }^{9}$ N. Golego, S. A. Studenikin, and M. Cocivera, J. Mater. Res. 14, 698 (1999).

${ }^{10}$ J. Hao and M. Cocivera, Appl. Phys. Lett. 79, 740 (2001).

${ }^{11}$ J. Hao, S. A. Studenikin, and M. Cocivera, J. Appl. Phys. 90, 5064 (2001).

${ }^{12}$ K. Binnemans and C. Gorller-Walr, Chem. Phys. Lett. 235, 163 (1995).

${ }^{13}$ B. G. Yacobi and D. B. Holt, Cathodoluminescence Microscopy of Inorganic Solids (Plenum, New York, 1990), p. 73.

${ }^{14}$ C. Falcony, A. Ortiz, J. M. Dominguez, M. H. Farias, L. Cota-Araiza, and G. Soto, J. Electrochem. Soc. 139, 267 (1992)

${ }^{15}$ A. Vecht, C. Gibbons, D. Davies, X. Jing, P. Marsh, T. Ireland, J. Silver, A. Newport, and D. Barber, J. Vac. Sci. Technol. B 17, 750 (1999).

${ }^{16}$ S. A. Bukesov, J. Y. Kim, and D. Y. Jeon, J. Appl. Phys. 91, 9078 (2002). 
Applied Physics Letters is copyrighted by the American Institute of Physics (AIP). Redistribution of journal material is subject to the AIP online journal license and/or AIP copyright. For more information, see http:/ojps.aip.org/aplo/aplcr.jsp

Copyright of Applied Physics Letters is the property of American Institute of Physics and its content may not be copied or emailed to multiple sites or posted to a listserv without the copyright holder's express written permission. However, users may print, download, or email articles for individual use. 